\title{
Transterritorializações do queer no Estado espanhol. De políticas e teorias inapropriáveis
}

\author{
Teoría queer. Políticas bolleras, \\ maricas, trans, mestizas.
}

CÓRDOBA, David; SÁEZ, Javier; VIDARTE, Paco (Eds.).

2. ed. Madrid: Egales, 2005. 257 p.

\section{À memória de Paco Vidarte}

Não há dúvidas de que os movimentos LGBT dos países ocidentalizados vivem um dos momentos mais intensos de sua história. As lutas a favor de garantias para uma vida digna e contra a homofobia se dispersaram e se consolidaram em diferentes frentes, em forma de movimentos sociais de caráter múltiplo, ora espontâneos, ora organizados, ocupando diferentes espaços políticos ou áreas acadêmicas. As lutas contra a pandemia do HIV e a favor do reconhecimento formal da mudança de gênero por parte de pessoas trans, do direito ao matrimônio e à adoção de filhas/ os são alguns dos pontos de embates mais visíveis, aos quais e contra os quais somam-se debates internos vitais, que questionam a misoginia, a transfobia e outras formas de exclusão interna aos movimentos LGBT, assim como a adesão à vida burguesa por determinados setores gays e lésbicos.

O mundo acadêmico se imbrica a essas lutas, contribuindo com ferramentas teóricas a uma compreensão crítica das dinâmicas sociais de opressão, mas também a um questionamento dos próprios movimentos. No entanto, como muitas/os das/os ensaístas de Teoría queer. Políticas bolleras, maricas, trans, mestizas insistem, o espaço acadêmico é tradicional e estruturalmente conservador, e a apropriação e o enrijecimento das práticas políticas e (des)identitárias de minorias marginais pela teoria queer são mais do que uma simples eventualidade.

Os doze ensaios e o poema que compõem o livro podem ser compreendidos como esforços dentro do Estado espanhol em dar conta da intensidade atual dos movimentos LGBT e contribuir para sua disseminação e seu fortalecimento. No entanto, se o título do livro marca um caráter acadêmico, o subtítulo aponta para deslocamentos e questionamentos que se confirmarão nos ensaios: a política aparece em primeiro lugar e os adjetivos escolhidos - bolleras (cuja tradução imperfeita 
seria "sapatonas"), maricas, trans e mestizas enfatizam certas agressividade e informalidade que o termo "queer" parece ter perdido ao conformar com a palavra "teoria" uma expressão de ares tão acadêmicos. "Queer es osos, zorras, lobos, perras, buitres, leonas, víboras. Um zoo no lógico", canta o poema de Sejo Carrascosa no meio do livro, deixando a marca mais explícita da opção pelo político e pelo informal próprios a qualquer movimento digno de seu nome.

No entanto, se o acadêmico e o intelectual têm sua importância subordinada ao político, tal não implica ligeireza ou desdém. Os/as ensaístas propõem reflexões rigorosas e originais, que abarcam temas e autoras queer da maior importância. São especialmente minuciosos os artigos de David Córdoba, que inaugura o livro, e o de Pablo Pérez Navarro. Córdoba, com o intuito de pensar a questão da identidade nos movimentos LGBT contemporâneos, se detém sobre os discursos de Michel Foucault e Freud relativos à sexualidade, bem como sobre os de Gayle Rubin e da tradição feminista francesa ligada ao materialismo (na qual se encontram, entre outras, Monique Wittig e Christine Delphy) sobre o sexo, traçando o caminho que permitiu a desnaturalização desses termos e a possibilidade de emergência da concepção do gênero como performatividade de Judith Butler. Em seu ensaio dedicado a essa autora, Pérez Navarro desenha as relações entre performatividade, abjeção e discurso de ódio (hate speech), ressaltando que a importância da obra de Butler não provém das respostas que ela propôs às indagações sobre o gênero, mas sim de sua opção por assumir os limites históricos do próprio pensamento crítico e, conseqüentemente, por deixar em aberto as possibilidades futuras de construção de identidades e da paisagem social.

Outros dois ensaios procuram intersecções teóricas arriscadas e mostram-se muito frutíferos. Beatriz Preciado, na busca de construir um corpo queer a partir de The Staight Mind, reintroduz o lesbianismo em um continuum homo-heterossexual, sem por isso abdicar do radicalismo de Wittig e, assim, insiste em uma construção do corpo que, sem menosprezar a lógica performativa, a supera, inscrevendo-se em um devir sapatão-lobo (bollo-lobo), que fará saltar pelos ares os regimes de opressão sobre as mulheres.

Por sua vez, Paco Vidarte retoma o receio ao acadêmico: "Ni lo queer nació en la universidad, ni nunca entrará en sus aulas de forma pacíficia", para depois matizar sobre a importância da filosofia para o pensamento cotidiano de um modo geral e, mais especificamente, sobre a importância da teoria de Derrida e Deleuze para a construção dos estudos queer, evidenciando assim suas raízes européias. No final do ensaio, Vidarte propõe pensar uma política queer a partir da concepção de multidão em Antonio de Negri, a qual apela à coletividade sem esfacelar a singularidade de cada pessoa que a compõe.

Se a tensão entre o teórico e o político é a mais claramente delineada ao longo do livro, há outra cuja importância é também capital, sendo especialmente interessante que a pensemos a partir do Brasil ou da América Latina: em que medida o "queer" ou a "teoria queer" constituem acontecimentos estadunidenses e em que medida são acontecimentos compartiIhados por outros (não)lugares, ou ainda, em que medida são universalizáveis ou passíveis de (re)apropriação por outros contextos?

A palavra "queer" é obviamente inglesa e, como nos mostra a ótima genealogia do termo empreendida por Alfonso Ceballos, é conhecida sua utilização como antônimo de straight ou respectable desde finais do século $\mathrm{XVI}$, sendo a apropriação positiva desse termo por parte de comunidades de homens homossexuais documentada pela primeira vez na década de 1910. Já o termo "teoria queer", como é bem sabido, foi cunhado em 1991 por Teresa de Lauretis.

No entanto, a palavra "queer" tem uma origem no indo-europeu - twerkw -, que em latim derivou em torquere (torcer, retorcer, serpentear - inclusive, no Estado espanhol houve uma tentativa, restritamente vingada, de traduzir o termo por torcido), o que implica uma etimologia compartilhada, ainda que de forma remota, entre todos os países ocidentalizados. Além disso, como bem o recordam, entre outros, os ensaios de Preciado, Javier Sáez, Carmen Romero e Eduardo Nabal, antes da canonização da expressão "teoria queer" por Lauretis, a palavra "queer" já era utilizada em escritos teóricos de acadêmicas chicanas, negras, lésbicas e de classe trabalhadora, ou seja, por aquelas que, ainda sendo formalmente cidadãs estadunidenses, careciam de reconhecimento pleno como tal e enraizavam seus desejos, ânsias e identidades para além de suas fronteiras.

Dessa forma, o termo "queer", cuja aceitação em âmbitos acadêmicos e militantes é ampla devido à sua capacidade 'subversiva' de negar uma referência concreta a qualquer 
identidade, é inapropriável também à fronteira estadunidense, ou mesmo à língua inglesa. $O$ queer tampouco deixa-se apreender geográfica e lingüisticamente. Não que o queer políico ou teórico estadunidense seja um entre outros. O ensaio de Sáez, por exemplo, esforça-se por mostrar como a reação dos grupos lésbicos e gays à pandemia do HIV nos Estados Unidos, e as crises nos movimentos feministas provocadas pelas críticas já mencionadas das feministas negras e lésbicas, e no movimento gay pelo repúdio ao seu aburguesamento, unidos à excepcional acolhida da obra foucaultiana por parte destes grupos, conformaram uma mistura que resultou extremamente potente. A influência sem igual do queer estadunidense, assim como da teoria que se apropriou de seu nome, é evidente sob qualquer ponto de vista. No entanto, isso não significa uma simples transposição de um saber estadunidense ao resto do mundo. Pelo contrário, muitas das condições históricas norte-americanas que permitiram o surgimento do queer são compartilhadas por outros Estados (a luta contra a pandemia do HIV, as cisões internas aos movimentos feministas e LGBTTI, etc.), assim como cada país traz suas próprias especificidades - no caso espanhol, entre outras, a recente ditadura franquista, o passado colonial ou a convivência com o outro interno: as/os ciganas/os.

Os ensaios que mais focam a especificidade do queer no Estado espanhol são os de Carmen Romero e Marcelo Soto, respectivamente sobre pós-colonialismo e literatura. Soto, compreendendo que as iniciadoras do queer, Wittig, Adrienne Rich, Gloria Anzaldúa e Audre Lorde, eram poetisas, defende que apenas a literatura pode romper com a linguagem dominante. Dessa maneira, o queer do Estado espanhol estaria na revista de poesia da década de 1980 Non Grata, do LSD, o "grupo de lesbiana que cambia al nombrarse", nos poemas de Leopoldo Maria Panero, ignorados pela própria teoria queer, ou nos livros de Manuel Puig, escritor do além-mar ex-colonial argentino.

Já em seu ensaio, Romero repassa 0 encontro entre teoria queer e pós-colonialismo nos países de língua inglesa, colocando a necessidade de se pensar como a recente migração ao território espanhol de latinas/os e africanos/as modifica o pensar LGBT. Lembra o que é óbvio, mas por regra ignorado: que muitas/os das/os imigrantes são trans, gays, intersex ou lésbicas. Ainda menciona a necessidade de futuramente serem incluídas reflexões sobre a população cigana, alteridade de difícil convivência interna ao Estado espanhol. O nome próprio Espanha, já terá chamado a atenção da/o leitor/a, é esquivado por quase todas/os articulistas, em clara escolha por ressaltar o caráter construído e violento de qualquer Estado-nação.

Outros três ensaios de caráter genealógico concentram-se principalmente sobre produções queer estadunidenses, ainda que não apenas: o de Eduardo Nabal, sobre o new queer cinema, o de José Manuel Martinez sobre sadomasoquisimo, e o de Desiré Rodrig e Helenta Torres sobre ciberqueer.

Nabal considera que o chamado "new queer cinema" não se constitui em um movimento cinematográfico propriamente, mas em "una serie de películas, festivales, críticos y espectadores que [...] han confluído en un modo similar de redefinir el cine gay y lésbico [...] como fenômeno social y como hecho cinematográfico". A emergência dessa "serie" se dá a partir da quebra com o modelo conservador gay, a qual foi possível a partir de um conjunto de filmes e reflexões sobre o cinema, que passam por cineastas como Jean Genet, Andy Wharol ou Jean Cocteau, o cine underground estadunidense ou a crítica feminista Laura Mulvey.

Por sua vez, Rodrig e Torres pensam o cyborqueer como fruto de tensões de gênero, mas também raciais e de classe, que encontram na indissociabilidade de organismo e tecnologia uma área para projetar alteridades inapropriáveis. As cyborqueer de autoras de ficção como Joanna Russ ou Octavia Butler aparecem, então, indissociáveis de outras formas de repúdio à lógica identitária, como a mestiza de Anzaldúa.

Fortemente influenciado por Foucault e por grupos estadunidenses de sado-masoquismo, Martínez ressalta a capacidade subversiva dessa prática, que trabalha e inverte as posições e relações de poder, dessexualizando o erótico, abrindo espaços para a exploração de prazeres corporais em que a dor (quando presente) não é um fim em si mesma, mas uma possibilidade de abertura ao prazer. Nesse sentido, a opinião de alguns grupos feministas que liga essa prática à violência e à misoginia está equivocada, ao ignorar o lema "seguro, saudável e consensual", próprio à ética sado-masoquista.

O artigo que por último apresento, sugestivamente denominado "La fuga de las bestias", é também interessante para se encaminhar uma conclusão. Nele, Fefa Vila Núñez pondera a possibilidade de ser-se estranha/o (rara/o) no momento atual de normalização, cujo marco é o midiático "matri- 
mônio gay". Espetando a euforia, lembra que as trans não se vêem em nada beneficiadas pelo acontecido e que outras formas de parentesco continuam invisibilizadas. Desse contexto político espanhol atual, ela adentra nos textos de Wittig e de Haraway, em suas construções de corpos sexuais ou ciborgues resistentes ao "heterrorismo", para retornar a Ricardo Llamas e Elvira Burgos Díaz que, dentro do Estado espanhol, iniciaram a resistência teórica ao aburguesamento gay e lésbico. Expõe, então, uma recusa de identidades LGBT que são respeitadas e celebradas como diferenças na medida em que abdicam de seu contexto radical, e conclama para que se construa um movimento queer radical no Estado espanhol, com alianças e ações coletivas que rompam com os contextos sociais, econômicos, étnicos e políticos.

O queer é, então, um devir inapropriável à lógica heteronormativa, cabendo à teoria LGBT não apreendê-lo em sistemas teóricos, por mais nômades que estes sejam, mas sim participar de sua força subversiva. Ao inscrever-se no devir queer, a teoria não perde seu caráter sistemático, mas enfatiza seu potencial criativo e assim insere-se no momento político e social atual e em suas perspectivas de transformações.

Post scriptum: no dia 29 de janeiro de 2008, faleceu Paco Vidarte, aos 37 anos. De vigor impressionante, publicou onze livros nos últimos dez anos, além de artigos e traduções de, entre outras/os, Monique Wittig e Jacques Derrida. Mostrou-se preocupado com tendências de submissão do político ao teórico. Como militante, indignava-se com os setores LGBT eufóricos com o matrimônio gay, enquanto o Estado espanhol continua tão homofóbico a ponto de diariamente as pessoas queer apanharem na rua ou de as crianças continuarem sendo aterrorizadas pelo bullying heteronormativo. Acreditava na necessidade de novas formas de luta LGBT, para além da reivindicação de direitos, solidárias a toda manifestação contra-opressiva. Como filósofo, debruçou-se sobre a obra de filósofos franceses contemporâneos, especialmente Derrida e sua preocupação com a singularidade e o acontecimento, mostrandose preocupado por tendências que procuram prescrever uma determinada maneira de ler 0 filósofo. Importava-lhe a amizade, o prazer, o humor, sem deixar de reivindicar a legitimidade do ódio para com os opressores. Alguns de seus escritos se encontram em sua página na web (http://www.pacovidarte.org/) e na de seu amigo Javier Sáez (http://www.hartza.com/).

Danilo de Assis Clímaco Universidade Federal de Santa Catarina 